OPEN ACCES $@$ :

\title{
Artificial sperm insemination in externally fertilised fish as a novel tool for ex situ and in situ conservation of valuable populations
}

\author{
Gyöngyi Gazsi ${ }^{1}$, Bence Ivánovics ${ }^{1}$, Roberta Berta Izabella ${ }^{1}$, Tamás Szabó ${ }^{2}{ }$ Zarski Daniel $^{3}$, \\ Balázs Kucska ${ }^{4}$, Béla Urbányi ${ }^{2}$, László Horváth ${ }^{2}$, Ferenc Müller ${ }^{5}$, Tamás Müller ${ }^{6, *}$ \\ ${ }^{1}$ Department of Environmental Toxicology, Institute of Aquaculture and Environmental Safety, Szent István Campus, \\ Hungarian University of Agriculture and Life Sciences, 2100 Gödölló, Páter K. u. 1, Hungary \\ ${ }^{2}$ Department of Aquaculture, Institute of Aquaculture and Environmental Safety, Department of Aquaculture, \\ Szent István Campus, Hungarian University of Agriculture and Life Sciences, 2100 Gödölló, Páter K. u. 1, Hungary \\ ${ }^{3}$ Institute of Animal Reproduction and Food Research of Polish Academy of Sciences, Tuwima 10 Str., 10-748 Olsztyn, Poland \\ ${ }^{4}$ Department of Applied Fish Biology, Institute of Aquaculture and Environmental Safety, Kaposvár Campus, Hungarian \\ University of Agriculture and Life Sciences 7400 Kaposvár, Guba S. u. 40, Hungary \\ ${ }^{5}$ Institute of Cancer and Genomic Sciences, College of Medical and Dental Sciences, University of Birmingham, \\ Vincent Drive, Edgbaston, B15 2TT Birmingham, UK \\ ${ }^{6}$ Department of Freshwater Fish Ecology, Institute of Aquaculture and Environmental Safety, Szent István Campus, \\ Hungarian University of Agriculture and Life Sciences, 2100 Gödöllő, Páter K. u. 1, Hungary
}

\begin{abstract}
Loss of genetic diversity and accumulation of deleterious mutations may lead to inbreeding depression in captive breeding. To address the problem of maintaining genetic diversity, we developed a new fish spawning method which offers flexibility in crossing diverse species when in vitro fertilisation (IVF) is not available. This method involves the collection of sperm from several males of ovuliparous fish; the sperm mix is then injected by catheter into the ovarian cavity of a female through the oviduct. We demonstrate, using zebrafish as a model for externally fertilised fish, that the sperm survives the ovarian conditions and can fertilise ovulated eggs, which are released from the body cavity during natural spawning. Wild type females were injected with reporter transgenic sperm from homozygous transgenic males before intended spawning with wild type males. The sperm injection method did not have an impact on reproductive parameters such as egg production or fertilisation rate compared to controls. In 25 successful spawning experiments, 20 females produced mixed genotype offspring comprising both transgenic and wild type larvae in varying ratios, indicating that the injected transgenic sperm efficiently competed with sperm released by non-transgenic wild type mating males, and both sperm types contributed to the fertilisation of the released eggs. This experiment provides proof of principle for increasing the genetic base of offspring of fish species, including that of many endangered fish species for which IVF is not available due to lack of timed induction of ovulation or when gametic release cannot be synchronised.
\end{abstract}

KEY WORDS: Genetic diversity $\cdot$ Sperm ovarian lavage $\cdot$ Zebrafish $\cdot$ Danio rerio

\section{INTRODUCTION}

Breeding fish in captivity (ex situ conservation) is a widely used management practice for endangered aquatic organisms. The main aim of such operations is to restock habitats and/or to restore vulnerable popu-

${ }^{*}$ Corresponding author: muller.tamas@uni-mate.hu lations or species that have become extinct in the wild (Philippart 1995, Ross et al. 2008). These practices have been criticised by the scientific community, with concerns being raised regarding genetic deterioration (e.g.loss of genetic diversity, accumulation of deleterious mutations or bottleneck effects, Woodworth et al. 
2002; loss of fitness to survival in the wild of captively grown fish, Milot et al. 2013). In many cases, however, there is no pragmatic alternative to sustain specific populations. Hatchery-based support of natural recruitment of valuable fish is still a very important part of the management of aquatic ecosystems (Ford et al. 2012, Trushenski et al. 2015). Therefore, efforts are being made towards genetically selective breeding operations of fish intended for restocking to natural waters (Boscari \& Congiu 2014), as well as developing protocols for specific training of the offspring to adapt to natural environments (Brown \& Day 2002). However, such operations lack standardised procedures, and training fish in captivity remains problematic. Therefore, alternative breeding methods are being sought involving in situ conservation where, apart from rehabilitation of natural habitats, eggs or very early life stages of fish are released into the natural environment to adapt naturally. However, due to predation, the survival rates for in situ conservation protocols are far lower than those attained by stocking of ex situ-reared, larger fish. It is possible to combine the 2 methods; ex situ conservation practical methodology (captive breeding) is used in the natural habitat of fish. To this end, controlled spawning in cages located in the natural habitat is performed, which allows control over the reproductive process, egg incubation and early growth of the offspring. Fish larvae at different stages can then be released from the cages (Tóth et al. 2016, Bridges et al. 2020). The cage spawning approach can be combined with traditional induced spawning, whereby the application of spawning agents (e.g. hormones or environmental stimuli) aids synchronization of spawning. However, the success of fish mating - especially those grown in cages or tanks - is often reduced due to lack of spawning behaviour or reduced effectiveness of spawning. Moreover, when schools of fish are held together, it is almost impossible to control the genotypes in the breeding process as there is no control over which fish will spawn within the enclosed group. Additionally, in such a case it is not possible to use cryopreserved sperm, which is an important tool in maintaining the genetic purity and diversity of the supported population. Another problem is that limitations on cage sizes influence the number of parents that can be used in paired- and group-spawning fish species. To address these concerns, a novel method of fish propagation is necessary in which the advantages of natural spawning efficiency can be combined with controlling genotype diversity. To achieve this goal, new technology for the control of genotypes is required, and gametes for the fertilisation of endangered species need to be made available of available gametes for fertilisation in endangered species needs to be overcome.

Munehara et al. (1989) described a subcategory of ovuliparous reproduction in elkhorn sculpin Alcichthys elongatus. The reproductive strategy of this species is internal gametic association (IGA), which refers to the association of male and female gametes inside the female reproductive tract followed by their release and subsequent fertilisation in the external environment. Müller et al. (2018a) imitated this strategy in an artificial breeding context, whereby collected sperm of ovuliparous common carp Cyprinus carpio were inserted into females by ovarian lavage and successfully contributed to fertilising released eggs. In that study, sperm samples were collected and injected into the ovary lobe with a catheter $12 \mathrm{~h}$ before ovulation in parallel with final hormonal induction. In another experiment (Müller et al. 2018b), a sperm and hormone mixture (carp pituitary extract, $\mathrm{CPE}$ ) was injected into the ovary lobes of African catfish Clarias garepinus $10 \mathrm{~h}$ before ovulation. The absorbed CPE induced ovulation and all females produced good quality eggs that developed normally after water activation of the gametes and fertilization. In neither of these experiments did ovarian fluid activate the spermatozoa, which thus maintained its biological activity for 10-12 h. These experiments demonstrate a proof of principle alternative to induced spawning. We hypothesise that genome diversity could be increased in pair-spawned or cohort-spawned fish by using ovarian lavage with mixed sperm samples. However, to prove this hypothesis, it is necessary to address the potential contribution to fertilisation of sperm stored in the ovary, on the one hand, and the native sperm from mating males, on the other.

In this study, our aim was to compare the fertilisation capability of naturally released and injected sperm in wild spawning fish. We chose zebrafish Danio rerio as a model species, as it is a well-established animal model for a wide range of research areas including reproduction biology and one in which mixing and monitoring of controlled genotypes are conveniently offered by transgenic reporter gene activity in offspring (Csenki et al. 2010).

\section{MATERIALS AND METHODS}

\subsection{Zebrafish lines and husbandry conditions}

Two zebrafish lines were used for the experiment. The wild-type zebrafish $\mathrm{AB}$ line has been bred for 
several years in the Zebrafish Laboratory of the Hungarian University of Agriculture and Life Sciences. The transgenic zebrafish line $T g-2.4 s h h$ : $g f p A B C$, carrying regulatory elements of the sonic hedgehog gene, was received from the Karlsruhe Institute of Technology (Ertzer et al. 2007) and has been reared under the same laboratory conditions as the $A B$ line. Experimental $A B$ fish were maintained in 11 polycarbonate tanks at a ratio of 1 female to 2 males. Transgenic males were kept together $(n=15$, standard length [SL]: $29 \pm 1.6 \mathrm{~mm}$ ) in a 31 polycarbonate tank with a water flow recirculated system (ZebTec, Tecniplast) through an upwelling bead filter at $25 \pm 2^{\circ} \mathrm{C}$ and were fed 3 times per day with commercial flakes (Sparos Zebra; 400-600 $\mu \mathrm{m}$ ) and live Artemia larvae grown from cysts (Ocean Nutrition $_{i}>230000$ nauplii $\mathrm{g}^{-1}$ ). The photoperiod was set at $14 \mathrm{~h}$ light:10 h dark.

The protocols of fish propagation and the template informed consent forms (Scientific Ethics Council for Animal Experimentation; XIV-001-2306-4/2012 and PE/EA/742-7/2020) were reviewed and approved by the Hungarian National Food Chain Safety Office, Animal Health and Animal Welfare Directorate of the Government Office of Pest County with respect to scientific content and compliance with applicable research subject regulations.

\subsection{Spawning}

To confirm the identification of offspring genotype, $2 \times 15 \mathrm{AB}$ females $(\mathrm{SL}=26.1 \pm 1.3 \mathrm{~mm}$ ) and $2 \times 30 \mathrm{AB}$ males $(\mathrm{SL}=26.6 \pm 1.3 \mathrm{~mm}$ ) were selected randomly. The $A B$ line began from unknown zebrafish source stocks bought from 2 pet shops (pet shop A and pet shop B) in Albany, Oregon, USA, in the early 1970s. Haploid progeny from $A B$ females were crossed with random $A B$ males for approximately 70 generations until the early 1990s, when 6 diploid progeny stocks (each from a distinct haploid female) were thoroughly intercrossed to produce the modern $A B$ line. The current $\mathrm{AB}$ source stock is maintained through large group-spawning crosses (Holden \& Brown 2018).

Traditional spawning approaches were used. Specifically, zebrafish propagation took place in $\sim 1.7 \mathrm{l}$ spawning tanks (Sloping Breeding Tank; ZebTec, Tecniplast) which feature a sloped interior or 'beach style' that facilitates and promotes zebrafish spawning (these tanks were used for all treatments). The tanks contain 2 interchangeable containers; the bottom of the inner vessel is perforated to facilitate egg collection and movement of fish post-spawning. A schematic of the breeding design is shown in Fig. 1. In the $1^{\text {st }}$ spawning treatment (Spawning I), 1 female and 1 male were introduced into each breeding tank; in Spawnings II, III and IV, 1 female and 2 males were placed into each breeding tank. Spawning took place the following morning, typically a few hours after the lights were turned on, as zebrafish reproduction is strongly influenced by photoperiod (Nasiadka \& Clark 2012). All fish were released to spawn according to the protocol of zebrafish fertilization and embryo isolation (www.zfic.org/common\%20techniques/mating. pdf). For all experiments, $1 \mathrm{l}$ breeding tanks (ZebTec, Tecniplast) were used. Water conditions were as follows: temperature $25^{\circ} \mathrm{C} ; \mathrm{pH} 7.0 \pm 0.2$; average conductivity $525 \mu \mathrm{S}$. Eggs were collected from every tank and placed into Petri dishes (diameter: $100 \mathrm{~mm}$ ) $2 \mathrm{~h}$ after the start of the light photoperiod. Eggs were incubated in a thermostat $\left(25.5^{\circ} \mathrm{C}\right.$, photoperiod was set at $14 \mathrm{~h}$ light:10 h dark) with daily water changes. After a $72 \mathrm{~h}$ incubation period, all eggs were checked and imaged with a Leica M205 FA microscope.

\subsection{Artificial insemination}

Tg-2.4shh:gfpABC homozygous males were removed from the breeding tank and anaesthetised with MS-222 (4.2 ml MS-222 per $100 \mathrm{ml}$ system water). After anesthetisation, the genital area was dried with a paper towel and sperm stripping occurred under a Leica M205 FA microscope. Sperm was obtained by gentle pressure on the sides of the $T g$-2.4shh:gfpABC males and collected using pipette tip (20-200 $\mathrm{\mu l}$, Gilson, thermo, yellow) and a halflength of G-1 glass capillary (length $90 \mathrm{~mm}$, external diameter $1 \mathrm{~mm}$, internal diameter $0.6 \mathrm{~mm}$; Narishige Scientific Instrument). One male's sperm sample $(\sim 1 \mu \mathrm{l}, 0.4-1.4 \mu \mathrm{l})$ was artificially inseminated into $1 \mathrm{AB}$ female. Females were anesthetised in the same way as males $1 \mathrm{~h}$ from the expected spawning time (dark/light changes). A glass capillary was inserted approximately $2 \mathrm{~mm}$ deep into the oviduct through the genital papilla of anaesthetised females using an automated pipette. Sperm samples were injected into the centre of the genital papille, i.e. sperm distribution was not directed into the 2 oviducts (random distribution), and then females were put back into the spawning tanks with $\mathrm{AB}$ males (Fig. 1). Resting periods varied among the spawning times depending on the experimental conditions and possibilities (Table 1). 
Transgenetic zebrafish line control

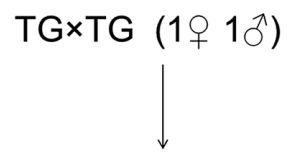

Fertilised eggs

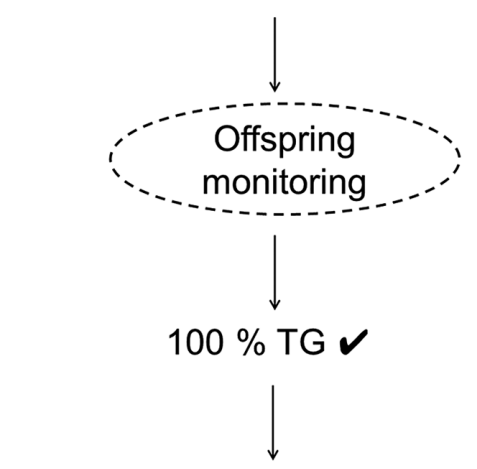

Sperm collection for sperm injection

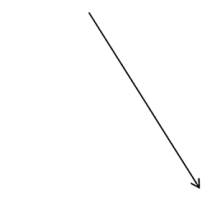

Artificial sperm insemination AB + (inj.TG sperm)

\section{Wild type contol (Spawning I, II, partly III)}

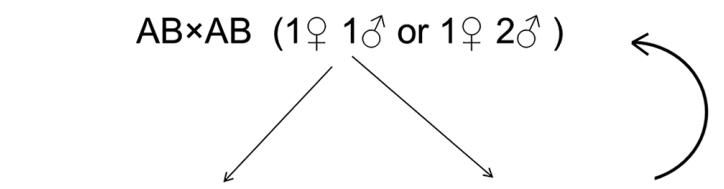

Fertilised eggs

Fertilised eggs $\varnothing$

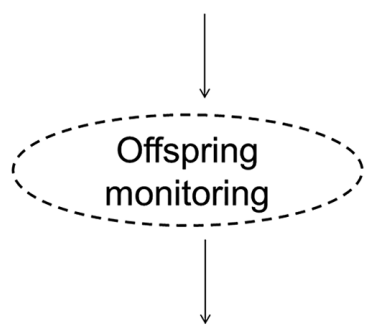

$100 \% A B \boldsymbol{V}$

Female donor for sperm injection

Sperm injection into gonad (Spawning III, IV)
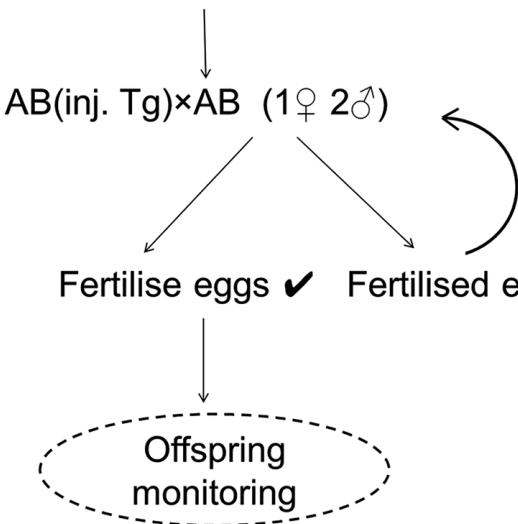

Fig. 1. Experimental design of the zebrafish artificial insemination experiment (treatments: Spawning I, II, III, and IV; see Section 2.2). TG: transgenic; AB: wild type zebrafish

\subsection{Analysis of offspring genotype}

The genotypes of the freshly hatched larvae were investigated using a Leica M205 FA microscope with Leica Application Suite X v.3.4.2.18368 software (LAS X; Leica Microsystems). Offspring originating

Table 1. Intervals of the zebrafish experimental spawning series (in days) (see Section 2.2 and Fig. 1)

\begin{tabular}{|lcccc|}
\hline \multirow{2}{*}{$\begin{array}{l}\text { No. of } \\
\text { females }\end{array}$} & I & II & III & IV \\
\cline { 2 - 5 } & 0 & 14 & 7 & 14 \\
$1-15$ & 0 & 7 & 15 & 25 \\
$16-30$ & & & \\
\hline
\end{tabular}

from transgenic sperm were counted upon detection of green fluorescence protein (GFP) expression using a GFP2 long pass filter, where the maximal excitation and emission values were 489 and $508 \mathrm{~nm}$, respectively. Females that either did not provide eggs/larvae from sperm insemination by the $3^{\text {rd }}$ and $4^{\text {th }}$ experimental cycles (females $8,12,14,29$ ) or died during the experiments (females 4, 10, 20, 24) were removed from further analysis.

\subsection{Statistical analysis}

Statistical analyses of fertilisation rates and egg number female ${ }^{-1}$ values were carried out by 1 -way 
ANOVA (with Tukey post hoc test) in SPSS v.22 for Windows. Treatment means were compared using a significance level of $\alpha=0.05$. The correlation between the ratio of fertilised egg yield to hatched transgenic larva was analysed by logarithmic correlation to determine the line of best fit to the data.

\section{RESULTS}

Our first question was whether the zebrafish sperm insemination protocol influenced the number of eggs released from treated females. As shown in Table 2, there was no statistical difference in the number of eggs released between the controls and Spawning III treatment individuals. Thus, sperm insemination did not influence the spawning success of the same female spawning naturally or after sperm injection. In the Spawning IV treatment, the females that were inseminated with sperm released more eggs than on previous occasions, but there was no significant difference in case of female was introduced with 1 or 2 males in spawning tanks (Table 2). There were no statistical differences $(p<0.05)$ among the total fertilisation rates independent of spawning method (natural spawning - artificial insemination) when the female was introduced with 1 or with 2 males in the spawning tanks (see Table 2).

Next, we investigated if sperm from naturally mating males successfully fertilised eggs during wild spawning or if the eggs were fertilised by artificially inseminated transgenetic sperm. To answer this question, we examined the phenotypic appearance of transgenic larvae, which are identified by GFP fluorescence by the emerging cells of larvae in which the sonic hedgehog regulatory elements activate the fluorescent reporter gene. Prior to the experiments, we confirmed that the transgenic males were homozygous and that all of their offspring inherited a copy of the expressed transgene (Fig. 2 and data not shown). We then confirmed that the control wild type males were indeed void of any fluorescence signal at the protruding mouth stage $(72 \mathrm{~h}$ post-fertilisation [hpf]) (Fig. 2). Finally, we carried out spawning experiments with the injected females and analysed their offspring for transgene activity at the protruding mouth stage (Table 2, Fig. 2).

As demonstrated in Table 3, there were 25 successful spawnings that resulted in larvae and 20 females that produced offspring including both transgenicreporter-positive larvae and $A B$ wild type larvae in varying fertilisation ratios. The average percentages of hatched transgenetic larva were $31.3 \pm 29.1 \%$ (all treated females: $\mathrm{n}=25$, min.-max.: $0-84.3 \%$ ) and $39.1 \pm 27.4 \%$ (all treated females which produced living embryos: $\mathrm{n}=20$, min.-max.: $3.8-84.3 \%$,). In 5 spawnings $(20 \%)$ there were no transgenetic larvae produced from the eggs.

\section{DISCUSSION}

In this study, we provide evidence for the generation of offspring with a mixed genetic background, including both transgenic and non-transgenic larvae originating from artificial insemination of transgenic fish sperm into wild type females followed by natural crossing with wild type, non-transgenic males. This experiment, carried out with zebrafish, provides proof of principle evidence for how genetic diversity of offspring could be increased by using mixed sperm insemination in an externally fertilising fish species, and we propose that this approach could be applied in similar externally fertilising fish species that are identified for genetic conservation efforts. Additionally, breeding programs aiming to increase the genetic diversity of economically important fish species, which are propagated through induced

Table 2. Summary of reproduction parameters in the zebrafish spawning experiment. Control: traditional spawning (Fig. 1). Superscript letters indicate significant difference (1-way ANOVA Tukey's post hoc test, $\mathrm{p} \leq 0.05$ ) in the investigated parameters

\begin{tabular}{|c|c|c|c|c|}
\hline \multirow{2}{*}{$\begin{array}{l}\text { Treatment } \\
\text { Spawning experiment } \\
\text { (no. of spawned } \\
\text { females) }\end{array}$} & \multirow{2}{*}{\multicolumn{2}{|c|}{$\begin{array}{cc}\text { Spawning I } & \text { Control } \\
(\mathrm{n}=11) & \text { Spawning II + } \\
& \text { Spawning III } \\
& \text { Control }(\mathrm{n}=14)\end{array}$}} & \multicolumn{2}{|c|}{ Sperm insemination } \\
\hline & & & $\begin{array}{l}\text { Spawning III } \\
\quad(\mathrm{n}=15)\end{array}$ & $\begin{array}{l}\text { Spawning IV } \\
\quad(\mathrm{n}=13)\end{array}$ \\
\hline Sex ratio & 1 우 $10^{7}$ & 1 o $\times 20^{7}$ & 1 o $\times 20^{\prime \prime}$ & $1 \stackrel{9}{ } \times 20^{7}$ \\
\hline $\begin{array}{l}\text { No. of eggs released } \\
(\text { mean } \pm \text { SD) }\end{array}$ & $34.8 \pm 27.3^{\mathrm{a}}$ & $68.6 \pm 36.7^{\mathrm{ab}}$ & $62.5 \pm 39.7^{\mathrm{ab}}$ & $97 \pm 81.8^{b}$ \\
\hline $\begin{array}{l}\text { Fertilisation rate }(\%) \\
\quad(\text { mean } \pm \mathrm{SD})\end{array}$ & $21.7 \pm 30.7^{a}$ & $43.3 \pm 29.4^{\mathrm{b}}$ & $42.9 \pm 27.5^{\mathrm{b}}$ & $41.5 \pm 23.7^{b}$ \\
\hline
\end{tabular}



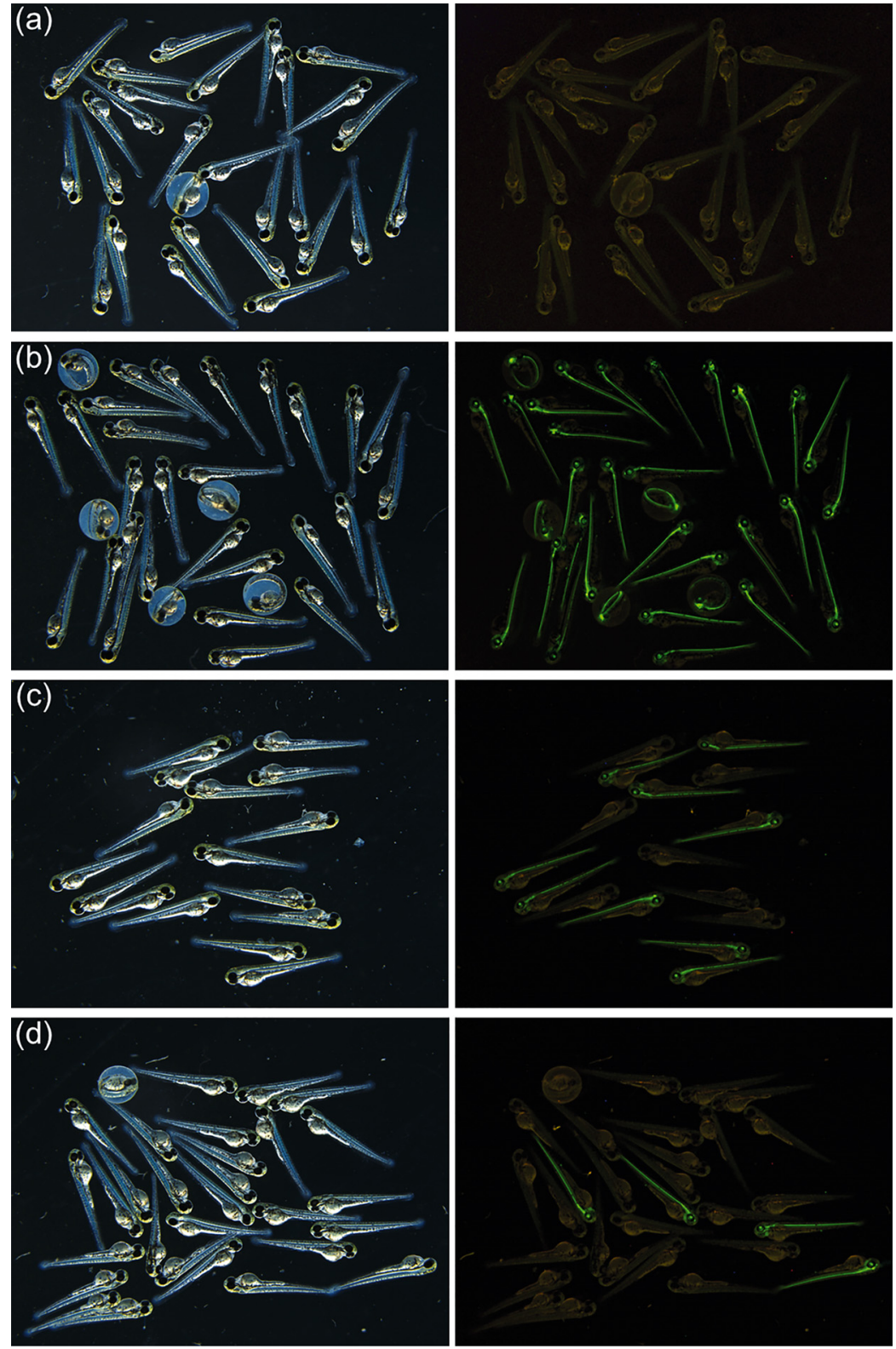

Fig. 2. Phenotypic appearance of offspring from different spawning treatments as a marker for transgenic (Tg) and wild type (AB) genotypes. Zebrafish larvae (72 h old) were imaged in the dark (left) and under fluorescence microscopy (right), resulting from crosses as follows: (a) $\mathrm{AB} \times \mathrm{AB}$ (Female \#7); (b) $\operatorname{Tg} \times \operatorname{Tg}($ Female \#1); (c) AB(inj.Tg) $\times$ AB (Female \# 21); and (d) AB(inj.Tg) $\times$ $\mathrm{AB}$ (Female \#16)

spawning could also benefit from our approach by using selected high-quality cryopreserved sperm samples and allowing their delivery to females which require pairing or group spawning to induce ovulation.

Our results show that the inseminated transgenic sperm takes part in the fertilisation process together with the sperm of the naturally spawning male and results in a mixture of both transgenic and non- transgenic larvae, with a proportion ranging from $0-84.3 \%$ transgenics. The reason for this large range may lie in suboptimal technical factors as well as yet unidentified differences in sperm quality or fitness resulting in sperm competition (Taborsky 1998). Such parameters may also include unidentified technical errors in methodology, such as inadvertent water contamination of sperm during handling, leading to premature activation of spermatozoa before ovulation of target eggs. Alternatively, suboptimal inseminated sperm delivery into the oviduct could lead to sperm leakage/ release from the inseminated females. Based on preliminary observations, there are several technological parameters that could be improved before adaptation to other fish species.

Injected sperm does not cause internal fertilization. In ovuliparous fish species, eggs are released from the female's body followed by their subsequent external fertilization or activation in the water. Dean et al. (2019) were the first to find living embryos in a non-copulatory, egg-laying teleost species (three-spined stickleback Gasterosteus aculeatus) and remove them from the ovary lobes at the eyed stage. Larvae were hatched and reared normally to adulthood under controlled conditions. Munehara et al. (1989) described a subcategory of ovuliparity, called IGA, which refers to the association of male and female gametes in the female reproductive tract followed by their release and subsequent fertilization in the external environment. Müller et al. (2020) investigated the sperm-ova interaction just after gamete stripping without water activation in the African catfish Clarias gariepinus using an electron microscope. Spermatozoa were distributed near the micropylar region and detected within the micropyle canal, similar to the observations of Munehara et al. (1989). We hypothesise that the spermatozoa are inactive near the micropyle region (or in it), and the closest sperm cell to the micropyle just after gamete release will fertilise the egg after water activation outside the female's body. 
Table 3. Reproductive parameters after artificial insemination of zebrafish females in Spawning III and IV treatments, showing contribution of inseminated sperm to offspring. AB: wild type; Tg: transgenic; hpf: hours post-fertilisation; $(-)$ unsuccessful spawning or eggs failed to fertilise

\begin{tabular}{|c|c|c|c|c|c|c|}
\hline \multirow{2}{*}{$\begin{array}{l}\text { No. } \\
\text { of } \\
\text { + }\end{array}$} & \multicolumn{3}{|c|}{$\begin{array}{c}\text { Spawning III } \\
\mathrm{AB} \circ \text { (Tg sperm inj.) } \times 2 \mathrm{AB} \mathrm{o}^{7}\end{array}$} & \multicolumn{3}{|c|}{ 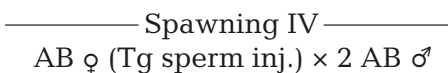 } \\
\hline & $\begin{array}{c}\text { No. of } \\
\text { eggs }\end{array}$ & $\begin{array}{l}\text { Survival } \\
72 \text { hpf }(\%)\end{array}$ & $\begin{array}{c}\text { Tg larvae } \\
(\%)\end{array}$ & $\begin{array}{c}\text { No. of } \\
\text { eggs }\end{array}$ & $\begin{array}{l}\text { Survival } \\
72 \text { hpf }(\%)\end{array}$ & $\begin{array}{c}\text { Tg larvae } \\
(\%)\end{array}$ \\
\hline 1 & 157 & 54.1 & 48.2 & 143 & 87.4 & 24.8 \\
\hline 2 & 31 & 83.9 & 3.8 & 71 & 54.9 & 20.5 \\
\hline 3 & - & - & - & 48 & 33.3 & 81.3 \\
\hline 5 & 15 & 60.0 & 0 & - & - & - \\
\hline 6 & - & - & - & 63 & 33.3 & 71.4 \\
\hline 7 & - & - & - & 67 & 62.7 & 28.6 \\
\hline 9 & 30 & 60.0 & 16.7 & - & - & - \\
\hline 11 & 99 & 2.0 & 0 & - & - & - \\
\hline 13 & 27 & 14.8 & 25.0 & - & - & - \\
\hline 15 & 28 & 25.0 & 14.3 & 14 & - & - \\
\hline 16 & 42 & 9.5 & 25.0 & 144 & 36.8 & 9.4 \\
\hline 18 & 93 & 64.5 & 46.7 & 71 & - & - \\
\hline 19 & 61 & 72.1 & 9.1 & - & - & - \\
\hline 21 & - & - & - & 144 & 11.1 & 56.2 \\
\hline 22 & 121 & 33.9 & 53.7 & 331 & 46.2 & 84.3 \\
\hline 23 & - & - & - & 61 & 42.6 & 77.1 \\
\hline 25 & 60 & 67 & 75.0 & - & - & - \\
\hline 26 & 65 & 66.2 & 0 & 73 & 6.8 & 0 \\
\hline 27 & 61 & 29.5 & 11.1 & 31 & - & - \\
\hline 30 & 48 & 2.1 & 0 & - & - & - \\
\hline
\end{tabular}

To rescue fragmented small populations in degraded habitats, efforts are often made to create new habitats (Tatár et al. 2017). To increase genetic diversity, 2 or more neighbouring inbred populations can be introduced into a newly created habitat (Fig. 3). According to our results, ovarian lavage with pooled sperm may increase genetic variability (Fig. 3: surrogate habitat $\times$ refreshed population) with reduced negative effects on the original population such as loss of genetic diversity, inbreeding depression, accumulation of deleterious mutations, bottleneck effects, and harbouring genetic degradation or decline as a result of allele fixation and loss (Beardmore 1983, Fernández \& Caballero 2001, Woodworth et al. 2002, Fuller \& Doyle 2018). The potential advantage of this method is that there is no genetic loss from a population because after sperm collection the males can be introduced back to their original habitat (Fig. 3: crossing strategy $\times$ sperm insemina-

In this study, freshly stripped sperm were injected into the ovary a few hours before the expected spawning time. We previously demonstrated that sperm insemination can be applied successfully $12 \mathrm{~h}$ before ovulation in common carp Cyprinus carpio and 10-36 h before ovulation in African catfish $C$. gariepinus (Müller et al. 2018a,b, 2019, 2020). In these studies, the potential effects of different latency times of the inseminated spermatozoa were investigated. However, there was no statistical difference in fertilisation and hatching rates between 5 and $36 \mathrm{~h}$ of latency in African catfish (Müller et al. 2020), indicating a surprisingly elongated viability and/or fertilisation capacity of the inseminated spermatozoa. The latency times used here are expected to be applicable to other fish species as well and offer a suitable time window for programmed spawning upon various hormonal treatments. Cryopreserved sperm can be used in this method (Müller et al. 2019).

To illustrate the potential advantages of the insemination approach in traditional fish rescue programs (in situ conservation) with other species, a schematic representation of the genotype combinations and comparisons of reproduction parameters are shown in Fig. 3. tion). In traditional fish rescue, the stocking of a small number of breeders (which does not risk the original populations) often fails or is only moderately successful; for example, due to insufficient density in which females do not find or are unable to choose mating pairs in the freshly introduced area (Fig. 3: crossing strategy $\times$ traditional fish rescue). In fish farming practice, larger numbers of males are stocked together with females to increase the chances of mating. This female to male ratio is 1:1.5-3 in common carp (Horváth et al. 2015), 1:2 in European catfish Silurus glanis (Horváth et al. 1984) and 1:1.2 in pikeperch Sander lucioperca (Horváth et al. 1984). Additional males, however, may cause more damage to the stocks of the original habitat and may lead to a critical loss in critically endangered populations. Stocking breeders for gene refreshment can fail when females show unintentional mating preference towards males from the same or closely related populations and will reduce the chance for gene exchange between segregated/isolated populations. A possible solution may be a controlled spawning program, for instance by using spawning cages and controlled parent selection (Fig. 3: crossing strategy $\times$ controlled spawning program). Besides securing directional spawning, 


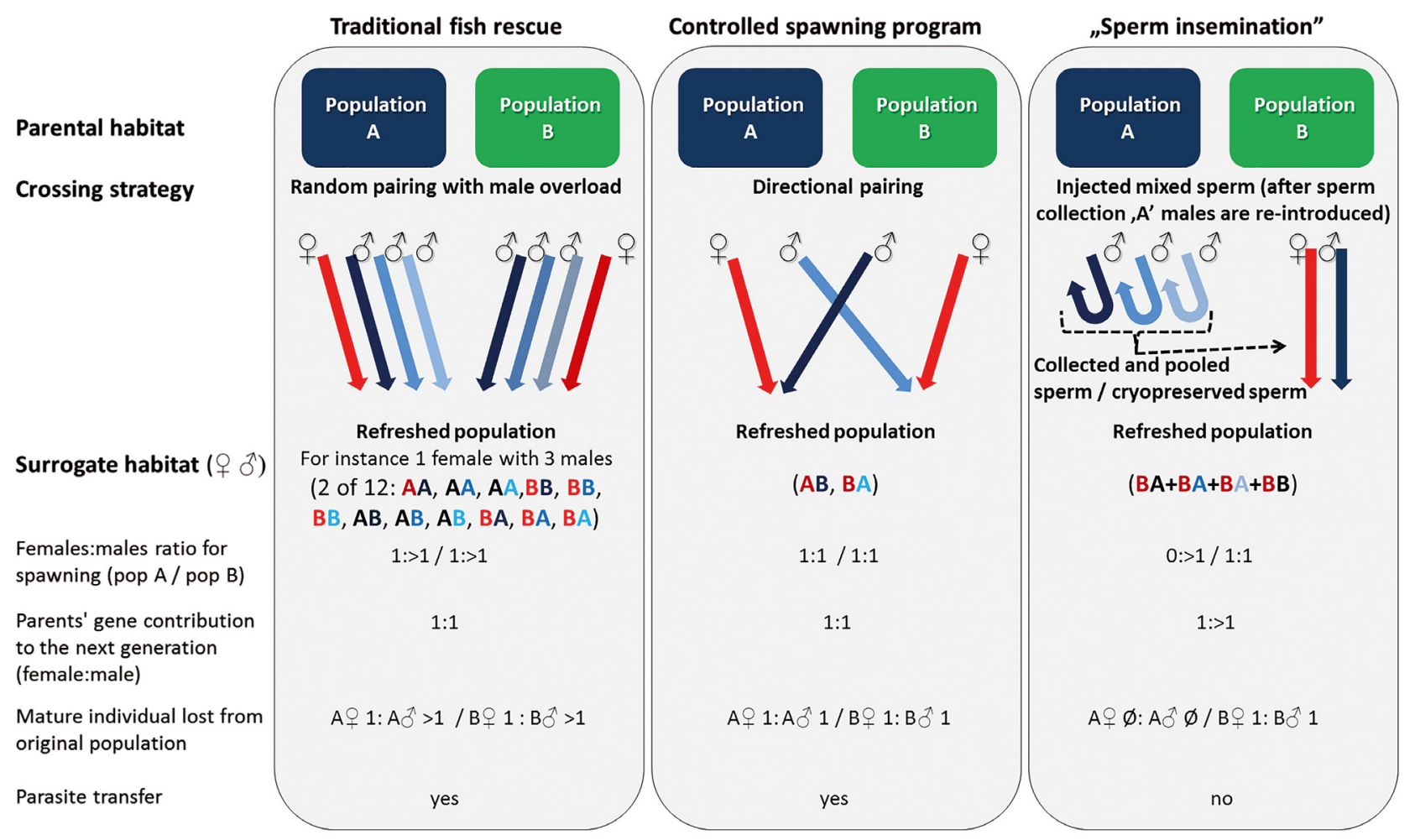

Fig. 3. Similarities and differences between traditional and artificial insemination-based fish propagation methods, with theoretical calculation of suitable number of parents and juveniles produced according to 3 different techniques. Populations A and B represent individuals from original habitats with small, isolated inbred populations with reduced genetic diversity. Straight blue shaded arrows: introduced males; curved blue arrows: males that were returned back to their original habitat after sperm collection; red arrows: introduced females; $\varnothing$ : no eggs or eggs failed to fertilise

the safety of larvae (Müller et al. 2019) is improved in the surrogate habitat (Tóth et al. 2016).

The disadvantage of the controlled spawning strategy is that the resulting genetic variability remains limited, as the genetic pool of offspring is limited to the availability and fecundity of parents selected from the original habitat (Fig. 3: crossing strategy $x$ traditional fish rescue, controlled spawning program). Since males continue to produce sperm after stripping, they can be reintroduced back into their original habitat, where they can breed naturally (Fig. 3: crossing strategy $\times$ sperm insemination). By using the sperm injection method, expansion of the genetic diversity of the offspring can be achieved in a relatively small spawning area compared to a traditional fish rescue setup in which the number of parents used remains limited. Theoretically, an additional potential advantage of the sperm injection method is that, because of the lack of direct contact between males and females, no ectoparasite exchange between the 2 sexes originating from different populations will occur (Fig. 3: parasite transfer $\times$ traditional fish rescue, controlled spawning program). In contrast, conventional breeding and directional breeding strategies will increase the chance of parasite transfer, and thus these procedures may cause more harm than benefit. Some extreme examples of parasite transfer occurred between differently sensitised subspecies European carp and koi carp to Thelohanellus nikolskii (Myxosporea) infection (Molnár 2002) or Anguillicolloides crassus infection from Anguilla japonica to $A$. anguilla and A. rostrata (Sprengel \& Lüchtenberg 1991, El-Shehabi et al. 2018).

\subsection{Gene changes between neighbouring inbred populations}

Endangered species often live in reduced or fragmented habitats, and as a result population fragmentation may occur, leading to inbreeding depression and a decrease in the genetic variability of the species. It is possible to increase the genetic diversity of isolated, inbred populations by applying the sperm injection method. In this procedure, males with excellent reproduction fitness are selected just before the spawning season and stripped of sperm; the sperm from several males is pooled and injected into 
one side of the ovarian lobe of anesthetised females. It is expected that when the females are released back to their home environment for natural spawning, eggs from the second lobe will be fertilised by males originating from the native habitat, while the injected lobe will release eggs that will be fertilised by the injected sperm. Thus, the genetic diversity of the native population is increased. There is no need for specialised equipment for short-term sperm storage because sperm quality parameters can be maintained within the first $10 \mathrm{~h}$ in cooling boxes (Pires et al. 2019). Only water contamination needs to be avoided. It is also possible to use sperm that has previously been cryopreserved and thawed for insemination, as was shown with C. gariepinus (Müller et al. 2019). The injected females can then be released where they were originally caught so that they can find their favoured spawning environment.

\subsection{Ex situ conservation}

The success of restocking programs for endangered species depends on the number and genetic diversity of the stocked individuals intended to maintain appropriate genetic variability (Ortega-Villaizan et al. 2011). In vitro fertilisation (IVF) and restocking numerous larvae or fingerlings could be an appropriate method to recover new or degraded habitats. IVF is generally used for ex situ conservation biology (captive breeding and rearing). Several fish species would benefit from such rescue efforts; however, IVF is not available for all species because fish may not respond to conventional hormonal injection, delicate broodstock may be sensitive to invasive hormone induction (Watson et al. 2009), or the fish may be too small (i.e. Vulnerable Umbra krameri, or Critically Endangered Romanichthys valsanicola, etc.). In some fish species like $U$. krameri there is no in vitro fertilisation technology available for propagation, and therefore the only possible method of artificial reproduction is induced spawning in a pen or tank (Kucska et al. 2016, Tatár et al. 2017). However, pen spawning can lead to bottleneck effects, as it strongly reduces the genetic diversity of the offspring due to the limited availability of mating pairs. The sperm insemination method, which allows a broad range of male genotypes to be used in fertilisation, may reduce the chance of such genetic deterioration.

In schooling fishes such as Anguilla spp., in situ conservation work is currently impossible due to the unique adaptation of the fish to inaccessible spawning environments. To circumvent this problem, sev- eral strategies are being developed to induce spawning of eel species in captivity. There are 2 types of induced propagation methods that are now available for European and Japanese eels in captivity. One is based on in vitro fertilisation and the other on induced spawning, whereby upon final hormonal administration females are placed into spawning tanks with 1-3 males to promote natural spawning. Horie et al. (2008) and Di Biase et al. (2016) reported that fertilisation and hatching were significantly higher with spontaneous spawning than with IVF. However, the success of induced spawning depends on brood preparation, which differs for the 2 sexes and may lead to variability due to differences in the quality of the sperm of successful male breeders. Spawning success is independent of the activation and fertilising ability of spawning males; thus, fertilisation success may be enhanced by combining previously selected, high-quality sperm for insemination of females which are then mated with well-conditioned males to enhance spawning success. The inseminated sperm is expected to be accumulated and to adhere to the micropyles (Müller et al. 2020), thus reducing the chance of spawning males outcompeting the inseminated sperm and thereby reducing the role of the spawning males in inducing ovulation. Additionally, the genetic basis of the offspring may be broadened by using pooled, preselected sperm samples from several males.

In this study, we have shown proof of principle for increasing the genetic diversity of offspring after sperm insemination in a genetic model species. We propose that our strategy should be tested on endangered species to prove our hypothesis in practice and to study how competition between sperm samples with different origins can contribute to the fertilisation of eggs released from the recipient females.

Acknowledgements. This work was supported by the National Research Development and Innovation Office of Hungary (NKFI K - 135824), the Higher Education Institutional Excellence Program FEKUT2019: TUDFO/47138/2019-ITM awarded by the Ministry of Human Capacities as well as the the Department for Angling and Fisheries, Ministry of Agriculture and the EFOP-3.6.3-VEKOP-16-2017-00008 project (the project is co-financed by the European Union and the European Social Fund) as well as the New National Excellence Programme (ÚNKP) - Research Scholarship Applications for PhD students and PhD candidates (ÚNKP-19-3) 2019/2020.

\section{LITERATURE CITED}

Beardmore JA (1983) Extinction, survival and genetic variation. In: Schonewald-Cox CM, Chambers SM, 
MacBryde B, Thomas WL (eds) Genetics and conservation: a reference for managing wild animal and plant populations. Benjamin/Cummings, Menlo Park, CA, p 125-151

Boscari E, Congiu L (2014) The need for genetic support in restocking activities and ex situ conservation programmes: the case of the Adriatic sturgeon (Acipenser naccarii Bonaparte, 1836) in the Ticino River Park. J Appl Ichthyol 30:1416-1422

Bridges CR, Nousdili D, Kranz-Finger S, Borutta F and others (2020) Hatching and release of Atlantic bluefin tuna larvae: theory and practice. Col Vol Sci Pap ICCAT 76: 408-420

Brown C, Day RL (2002) The future of stock enhancements: lessons for hatchery practice from conservation biology. Fish Fish 3:79-94

Csenki ZS, Zaucker A, Kovács B, Lefler KK and others (2010) Intraovarian transplantation of stage I-II follicles results in viable zebrafish embryos. Int J Dev Biol 54: 585-589

* Dean LL, Robertson S, Mahmud M, MacColl ADC (2019) Internal embryonic development in a non-copulatory, egg-laying teleost, the three-spined stickleback, Gasterosteus aculeatus. Sci Rep 9:2395

Di Biase A, Casalini A, Emmanuele P, Mandelli M, Lokman PM, Mordenti O (2016) Controlled reproduction in Anguilla anguilla (L.): comparison between spontaneous spawning and stripping-insemination approaches. Aquacult Res 47:3052-3060

El-Shehabi F, Marcogliese DJ, Oliveira K (2018) New North American paratenic hosts of Anguillicola crassus and molecularly-inferred source of invasion. Aquat Invasions 13:231-246

Ertzer R, Muller F, Hadzhiev Y, Rathnam S, Fischer N (2007) Cooperation of sonic hedgehog enhancers in midline expression. Dev Biol 301:578-589

Fernández J, Caballero A (2001) A comparison of management strategies for conservation with regard to population fitness. Conserv Genet 2:121-131

Ford M, Murdoch A, Howard S (2012) Early male maturity explains a negative correlation in reproductive success between hatchery-spawned salmon and their naturally spawning progeny. Conserv Lett 5:450-458

Fuller MR, Doyle MW (2018) Gene flow simulations demonstrate resistance of long-lived species to genetic erosion from habitat fragmentation. Conserv Genet 19: 1439-1448

Holden LA, Brown KH (2018) Baseline mRNA expression differs widely between common laboratory strains of zebrafish. Sci Rep 8:4780

Horie N, Utoh T, Mikawa N, Yamada Y, Okamura A, Tanaka S, Tsukamoto K (2008) Influence of artificial fertilization methods of the hormone-treated Japanese eel Anguilla japonica upon the quality of eggs and larvae. Bull Jpn Soc Sci Fish 74:26-35 (in Japanese with English Abstract)

Horváth L, Tamás G, Tölg I (1984) Special methods in pond fish husbandry. Akadémia Kiadó, Budapest

Horváth L, Tamás G, Coche AG, Kovács E, Moth-Poulsen T, Woynarovich A (2015) Training manual on the artificial propagation of carps. A handout for on-farm training workshops on artificial propagation of common carp and Chinese major carps in Central and Eastern Europe, the Caucasus and Central Asia, $2^{\text {nd }}$ edn (revised). FAO REU, Budapest
Kucska B, Kabai P, Hajdú J, Várkonyi L and others (2016) Ex situ protection of the European mudminnow (Umbra krameri Walbaum, 1792): spawning substrate preference for larvae rearing under controlled conditions. Arch Biol Sci 68:61-66

Milot E, Perrier C, Papillon L, Dodson JJ, Bernatchez L (2013) Reduced fitness of Atlantic salmon released in the wild after one generation of captive breeding. Evol Appl 6:472-485

*Molnár K (2002) Differences between the European carp (Cyprinus carpio carpio) and the coloured carp (Cyprinus carpio haematopterus) in susceptibility to Thelohanellus nikolskii (Myxosporea) infection. Acta Vet Hung 50:51-57

Müller T, Horváth L, Szabó T, Ittzés I and others (2018a) Novel method for induced propagation of fish: sperm injection in oviducts and ovary/ovarian lavage with sperm. Aquaculture 482:124-129

Müller T, Kucska B, Horváth L, Ittzés Á and others (2018b) Successful, induced propagation of African catfish (Clarias gariepinus) by ovarian lavage with sperm and hormone mixture. Aquaculture 485:197-200

* Müller T, Szabó T, Kollár T, Csorbai B and others (2019) Artificial insemination of African catfish (Clarias gariepinus) using cryopreserved sperm. Theriogenology 123: $145-150$

Müller T, Ács É, Beliczky G, Makk J and others (2020) New observations about fertilization capacity and latency time of sperm inseminated into ovary in African catfish (Clarias gariepinus) as an oviparous model fish. Aquaculture 522:735109

* Munehara H, Takano K, Koya Y (1989) Internal gametic association and external fertilization in the elkhorn sculpin, Alcichthys alcicornis. Copeia 1989:673-678

Nasiadka A, Clark MD (2012) Zebrafish breeding in the laboratory environment. ILAR J 53:161-168

Ortega-Villaizan MD, Noguchi D, Taniguchi N (2011) Minimization of genetic diversity loss of endangered fish species captive broodstocks by means of minimal kinship selective crossbreeding. Aquaculture 318:239-243

* Philippart JC (1995) Is captive breeding an effective solution for the preservation of endemic species? Biol Conserv 72: 281-295

* Pires LB, Sanches EA, Romagosa E, Filho RACC, Nass RAR, Lopera-Barrero NM, Povh JA (2019) Sperm quality of Colossoma macropomum after room temperature and cold storage. J Appl Ichthyol 35:747-753

* Ross RM, Quetin LB, Martinson DG, Iannuzzi RA, Stammerjohn SE, Smith RC (2008) Palmer LTER: patterns of distribution of five dominant zooplankton species in the epipelagic zone west of the Antarctic Peninsula, 19932004. Deep Sea Res II 55:2086-2105

Sprengel G, Lüchtenberg H (1991) Infection by endoparasites reduces maximum swimming speed of European smelt Osmerus eperlanus and European eel Anguilla anguilla. Dis Aquat Org 11:31-35

Taborsky M (1998) Sperm competition in fish: 'bourgeois' males and parasitic spawning. Trends Ecol Evol 13: 222-227

* Tatár S, Bajomi B, Specziár A, Tóth B and others (2017) Habitat establishment, captive breeding and conservation translocation to save threatened populations of the Vulnerable European mudminnow Umbra krameri. Oryx 51:718-729

Tóth B, Sevcsik A, Várkonyi L, Urbányi B, Müller T (2016) A lápi póc (Umbra krameri) ívatóketreces szaporítása Far- 
moson (European mudminow (Umbra krameri) propagation in cages in Farmos). Magyar Haltani Konferencia XII (Abstract)

Trushenski JT, Blankenship HL, Bowker JD, Flagg TA and others (2015) Introduction to a special section: hatcheries and management of aquatic resources (HaMAR) - considerations for use of hatcheries and hatchery-origin fish. N Am J Aquaculture 77:327-342

Editorial responsibility: Brendan Godley,

University of Exeter, Cornwall Campus, UK

Reviewed by: 3 anonymous referees
Watson CA, Hill JE, Graves JS, Wood AL, Kilgore KH (2009) Use of a novel induced spawning technique for the first reported captive spawning of Tetraodon nigroviridis. Mar Genomics 2:143-146

* Woodworth LM, Montgomery ME, Briscoe DA, Frankham $\mathrm{R}$ (2002) Rapid genetic deterioration in captive populations: causes and conservation implications. Conserv Genet 3:277-288

Submitted: May 26, 2020

Accepted: March 9, 2021

Proofs received from author(s): June 10, 2021 